\title{
A rapid translocation of photoassimilates from source organs maintains grain yield in cowpea subjected to drought stress during grain filling
}

\author{
C. EGASHIRA, Y. HASHIGUCHI, E. KURAUCHI, Y. TATSUMI, A.C.S. NAKAGAWA, \\ N. HAMAOKA, T. YUASA ${ }^{\dagger}$, M. IWAYA-INOUE, and Y. ISHIBASHI* \\ Crop Science Laboratory, Faculty of Agriculture, Kyushu University, Nishi-ku, Fukuoka 819-0395, Japan
}

\begin{abstract}
We examined the influence of drought stress during grain filling on grain yield to investigate changes in assimilates in sink and source organs. When plants were subjected to drought stress from the start of grain filling until harvest, the photosynthetic rate rapidly decreased. Grain dry mass during maturation was not significantly different between the control and drought-stressed plants. Under drought stress conditions, starch content in source organs (peduncle, leaf, petiole, stem, and root) was significantly lower than in corresponding organs of control plants; the greatest difference was seen in leaves. Consistent with this observation, $\alpha$ - and $\beta$-amylase activities in leaves significantly increased within the first $6 \mathrm{~d}$ of drought stress. We conclude that in cowpea subjected to drought stress during grain filling, the grain yield is maintained, despite a dramatic decrease in photosynthetic rate, by translocation of photoassimilates from source organs.
\end{abstract}

Additional key words: $\alpha$ - and $\beta$-amylase, photosynthetic rate, starch, Vigna unguiculata.

\section{Introduction}

Drought stress induces a range of physiological and biochemical responses in plants. These responses include stomatal closure, repression of cell growth and photosynthesis, and activation of respiration. Consequently, drought stress is the primary cause of crop loss worldwide, reducing average yields of most major crop plants (Boyer 1982, Bray et al. 2000).

Cowpea (Vigna unguiculata) is an important legume crop that provides a source of protein-rich food. It is grown in semi-arid western Africa, where rainfall is characteristically low (300 - $600 \mathrm{~mm}$ annually) (Fussell et al. 1991, Ogbonnaya et al. 2003). Although cowpea is recognized as drought tolerant compared with many other crops, drought stress experienced during critical growth stages can lead to substantial reduction in yield (Turk et al. 1980, Shouse et al. 1981). Imamura et al. (2010) demonstrated that the stomata of cowpea plants rapidly close in response to drought stress during vegetative growth, reducing water loss. Whereas a short period of drought at the vegetative stage has little effect on the seed yield of cowpea (Muchero et al. 2008), drought stress at the reproductive stage causes a significant loss (Hiler et al. 1972).
In soybean, drought stress in pod development stage significantly increases the rate of pod abortion, thus decreasing final seed yield (Liu et al. 2003). Saito et al. (1999) reported that from the late flowering stage to the young pod stage, soybean is susceptible to sink abortion, and that the drought stress at time of seed growth stage is the most critical factor determining the degree of yield loss. Brevedan and Egli (2003) also reported that short periods of drought stress during seed filling in soybean caused substantial yield reduction owing to the presence of fewer and smaller seeds rather than pod abortion.

Under drought stress induced in a pot experiment, cowpea is tended to be more sensitive to water deficits at the flowering stage than at the vegetative stage (Hiler et al. 1972). Shouse et al. (1981) reported 44.5 and $39 \%$ seed yield decrease when cowpea plant was water stressed at flowering and pod-filling stages, respectively. Our group has previously reported that drought stress at the flowering stage in cowpea reduced the numbers of flowers and pods; this loss of reproductive tissue was the main factor contributing to yield loss under drought stress (Sakamoto et al. 2012). However, these studies in cowpea were limited to the effect of drought stress at the flowering stage (or early reproductive stage), and the effect of drought stress at grain filling stage is still not clear.

Submitted 22 August 2019, last revision 16 October 2019, accepted 22 October 2019.

Abbreviations: HPLC - high-performance liquid chromatography; NSS - nonstructural saccharide; $\mathrm{P}_{\mathrm{N}}$ - net photosynthetic rate; SWC soil water content;

Acknowledgments: This work was supported by the JSPS KAKENHI Grant Number JP23380013. We are grateful to Dr. Ryoji Matsunaga (JIRCAS) for provision of cowpea seeds, which were bred by IITA.

$\uparrow$ Present Address: Faculty of Agriculture, Miyazaki University, Miyazaki, Japan

* Corresponding author; fax: (+81) 92802 4556, e-mail: yushi@agr.kyushu-u.ac.jp 
Approximately $64 \%$ of the carbon in cowpea grain is dependent on assimilates produced by photosynthesis in leaves at grain filling (Pate et al. 1983), however, the stomata of cowpea plants rapidly close in response to drought stress (Bates and Hall 1981, Osonubi 1985). Therefore, drought stress during grain filling stage reduce the amount of photoassimilates available to grain filling by decreasing the photosynthetic rate. The objective of the present research was to demonstrate the effect of drought stress during grain filling on grain yield in cowpea with a focus on changes in assimilates, such as starch and sucrose, in sink and source organs.

\section{Materials and methods}

Plants and treatments: Cowpea [Vigna unguiculata (L.) Walp. an obligate short-day cv. IT99K-241-2] was sown in pots filled with moistened sand in a greenhouse at Kyushu University, Japan, in 2007 and 2009. Basal fertilizer $\left(\mathrm{N}: \mathrm{P}_{2} \mathrm{O}_{5}: \mathrm{K}_{2} \mathrm{O}=3: 10: 10\right)$ was applied at a rate of $5 \mathrm{~g} \mathrm{pot}^{-1}$. The seedlings were subjected to short-day treatment (10-h photoperiod) for $14 \mathrm{~d}$ to induce flower bud formation. Then, temperature in the greenhouse was 25 to $37{ }^{\circ} \mathrm{C}$, natural irradiance and photoperiod. At the start of the grain filling stage (10 d after flowering), drought stress was imposed by withholding irrigation until harvest, and regular irrigation was maintained in control. In the 2009 experiment, all but twelve pods were removed from each plant at the start of the drought treatment. Seed yield and yield components (number of pods, number of seeds per pod, and 100-seed mass) were measured after all pods had matured. The pots were arranged in a completely randomized design.

At the completion of the treatment period, the soil down to $10-\mathrm{cm}$ depth and bottom of pot were taken from each pot and weighed immediately to obtain its wet mass. It was then dried at $90^{\circ} \mathrm{C}$ for $48 \mathrm{~h}$, and the wet and dry masses were used to estimate soil water content (SWC). SWC was calculated as [(soil wet mass) - (soil dry mass)]/ (soil dry mass). In this study, SWC in the $10-\mathrm{cm}$ depth was nearly identical to that in the bottom of pot.
Photosynthesis measurements: Net photosynthetic rate $\left(\mathrm{P}_{\mathrm{N}}\right)$ was measured in cowpea leaves using a portable photosynthesis system (LCpro, ADC Bioscientific, Hoddesdon, UK) at $30^{\circ} \mathrm{C}$ in the morning (08:00 - 11:00). The quantum flux density of radiation at leaf surface, flow rate, and leaf temperature in the chamber were maintained at $1500 \mu \mathrm{mol} \mathrm{m} \mathrm{m}^{-2} \mathrm{~s}^{1}, 200 \mu \mathrm{mol} \mathrm{s}{ }^{-1}$, and $30{ }^{\circ} \mathrm{C}$, respectively. The $\mathrm{P}_{\mathrm{N}}$ was measured at an ambient $\mathrm{CO}_{2}$ concentration of $400 \mu \mathrm{mol} \mathrm{mol}{ }^{-1}$.

Sucrose, starch, and nonstructural saccharide (NSS) content: Sucrose and starch content was measured according to Phan et al. (2013). Sucrose was determined using a high-performance liquid chromatography (HPLC) system equipped with refractive index detector RID-10A, liquid pump $L C-10 A D$, column oven CTO-10A (all from Shimadzu, Kyoto, Japan), and Shodex sugar column SP0810 (Showa Denko K.K, Kanagawa, Japan). For starch determination, the assay that is used is based on the hydrolysis of the starch by amyloglucosidase $\left(120 \mathrm{U} \mathrm{cm}^{-3}\right.$, $100 \mathrm{mM}$ acetate buffer, $\mathrm{pH}$ 4.5) from Rhizopus sp. (Sigma-Aldrich, St. Louis, MO, USA). The starch content was calculated by the glucose content produced by the hydrolysis reaction; the NSS content was indicated by the total of starch and soluble sugars (sucrose, glucose, and fructose) detected by HPLC.

Enzyme activity: Leaf $\alpha$ - and $\beta$-amylase activities were measured using an Amylase HR reagent kit (Megazyme International, Wicklow, Ireland) according to the manufacturer's instructions. Spectrophotometric measurements were carried out in $1-\mathrm{cm}$ cuvettes at $410 \mathrm{~nm}$ by using a spectrophotometer (U-1800, Hitachi, Tokyo, Japan). One unit of enzyme activities was defined as the amount of the enzymes required for release of $1 \mu \mathrm{mol}$ of $p$-nitrophenol in 1 min under the defined assay conditions.

Statistical analysis: There were five replications of each treatment (i.e., drought and control). The significant difference between the treatments was analyzed using Student's $t$-test. Statcel 3 was used as a software for the two-way ANOVA.

Table 1. Effect of drought stress during grain filling on yield and yield components of cowpea. Means \pm SDs, $n=11(2007), n=7$ (2009); ** - significant at $5 \%$ level, n.s. - not significant; values followed by the same letter within a column are not significantly different at $1 \%$ level based on the Tukey-Kramer's test.

\begin{tabular}{|c|c|c|c|c|c|}
\hline & & $\begin{array}{l}\text { Yield } \\
{\left[\text { g plant }^{-1} \text { ] }\right.}\end{array}$ & $\begin{array}{l}\text { Pod number } \\
\left.\text { [plant }^{-1}\right]\end{array}$ & $\begin{array}{l}\text { Seed number } \\
{\left[\operatorname{pod}^{-1}\right]}\end{array}$ & $\begin{array}{l}100 \text { grain mass } \\
{[\mathrm{g}]}\end{array}$ \\
\hline \multirow[t]{2}{*}{2007} & control & $27.3 \pm 5.8 \mathrm{a}$ & $24.5 \pm 1.3 \mathrm{a}$ & $5.4 \pm 0.9 a$ & $21.4 \pm 3.4 \mathrm{a}$ \\
\hline & drought & $23.0 \pm 5.3 a$ & $18.3 \pm 4.7 b$ & $6.1 \pm 1.3 a$ & $21.2 \pm 2.9 \mathrm{a}$ \\
\hline \multirow[t]{2}{*}{2009} & control & $14.1 \pm 1.7 b$ & $11.3 \pm 2.0 \mathrm{c}$ & $5.6 \pm 0.8 \mathrm{a}$ & $22.5 \pm 0.7 \mathrm{a}$ \\
\hline & drought & $12.4 \pm 0.9 b$ & $11.6 \pm 2.4 \mathrm{c}$ & $5.2 \pm 0.2 \mathrm{a}$ & $20.0 \pm 1.1 \mathrm{a}$ \\
\hline Year & & $* *$ & $* *$ & n.s. & n.s. \\
\hline Treatment & & n.s. & n.s. & n.s. & n.s. \\
\hline Year $\times$ treat. & & n.s. & n.s. & n.s. & n.s. \\
\hline
\end{tabular}




\section{Results and discussion}

Drought stress during grain filling often results in drastic yield losses; for example, yield of soybean subjected to drought stress (50\% SWC compared with control) during grain filling was $56 \%$ lower than in the control (Saito et al. 1999). However, in cowpea plant, little is known about the effect of drought stress at grain filling, although

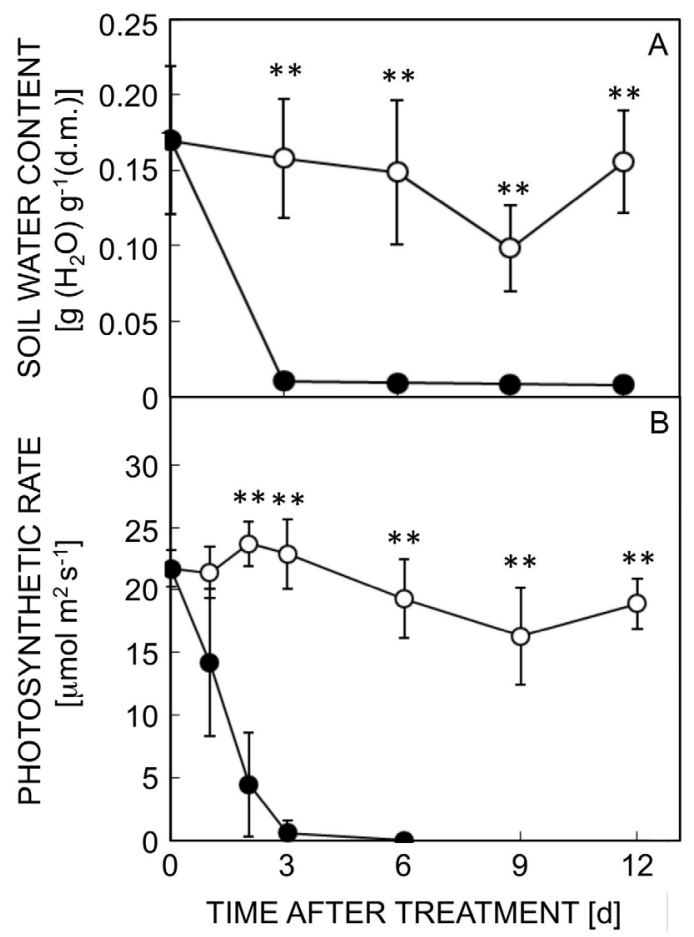

Fig. 1. Effect of drought stress during grain filling on soil water content $(A)$ and net photosynthetic rate $(B)$ in 2009 (open circles - control; closed circles - drought stress). Means \pm SDs, $n=5$, asterisks indicate significant differences $(P<0.01$, Student's $t$-test). it had been reported that flowering stage was the most drought sensitive stage (Shouse et al. 1981). In the present study, the drought stress during grain filling in cowpea did not significantly change the number of seeds or grain yield in either of two years, although the pod number per plant significantly decreased in 2007 (Table 1). In 2009, we removed all but twelve pods per plant at the start of the drought treatment to exclude the effects of pod abortion by drought stress. Brevedan and Egli (2003) reported that short periods of drought stress (40\% SWC compared with control) during seed filling in soybean caused substantial yield reduction due to the presence of fewer and smaller seeds $(25-33 \%)$. However, in cowpea, drought stress at grain filling hardly reduced 100 -grain mass and yield in 2009.

Then, here a question arises, how does cowpea maintain grain yield despite the rapid and significant reduction in photosynthetic rate induced by the drought stress during grain filling (Fig. 1)? To answer this query, the effects of drought stress on the NSS content in sink (seed) and source organs (pod, peduncle, leaf, petiole, stem, and root) were examined (Fig. 2). At $6 \mathrm{~d}$ after drought stress, NSSs were hardly accumulated in all source organs. However, the NSS content in sink organ (seed) increased similarly to control at $6 \mathrm{~d}$ after drought stress. In addition, the two-way ANOVA confirmed an interaction between stress treatment and organs. These results indicated that translocation of photoassimilates from source organs were involved in the maintenance of 100-grain mass under drought stress. We, therefore, examined the effect of drought stress on the degradation of starch in source organs (pod, peduncle, leaf, petiole, stem, and root). After $3 \mathrm{~d}$ of drought treatment, the dry masses of leaf and petiole were lower than those of the control, although the dry mass of roots was higher than that that of control (Fig. 3A-F). The drought treatment for $6 \mathrm{~d}$ reduced the starch content drastically in all organs except in pods, particularly in leaves and petioles (Fig. $3 G L$ ). The sucrose content of drought-stressed organs except for root

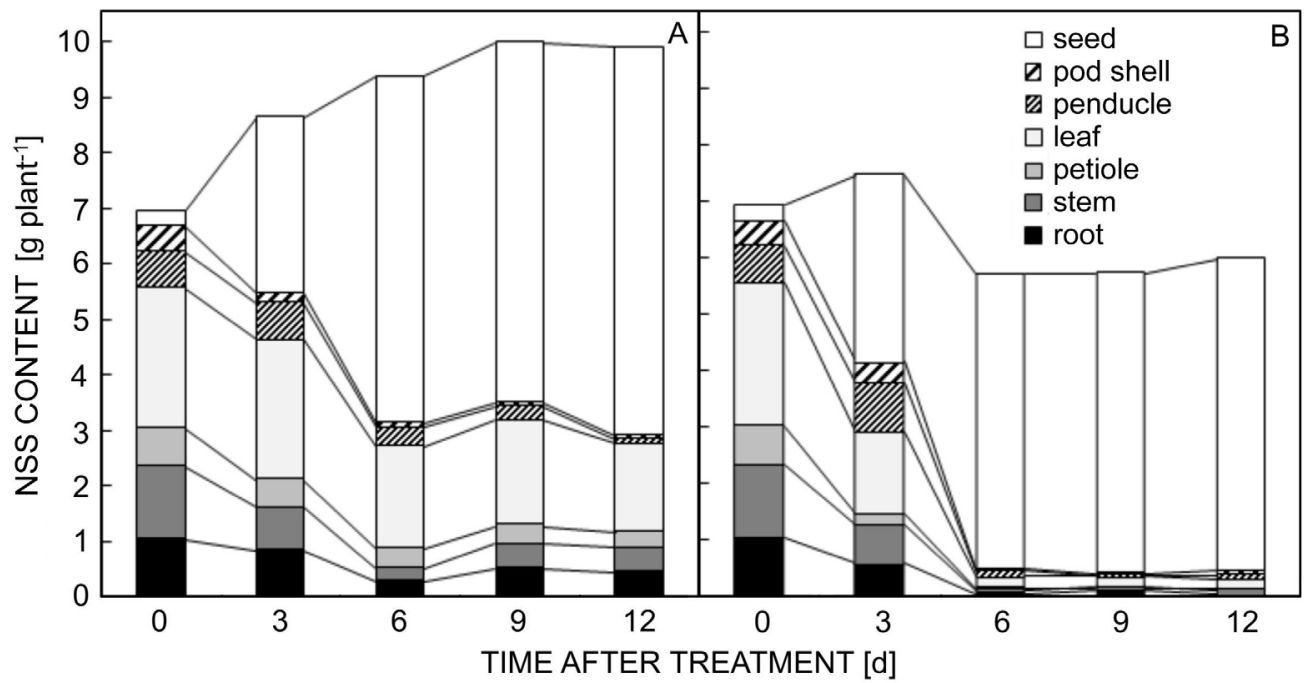

Fig. 2. Nonstructural saccharide (NSS) content of sink and source organs of cowpea under control conditions $(A)$ and drought stress $(B)$ during grain filling in 2009. 

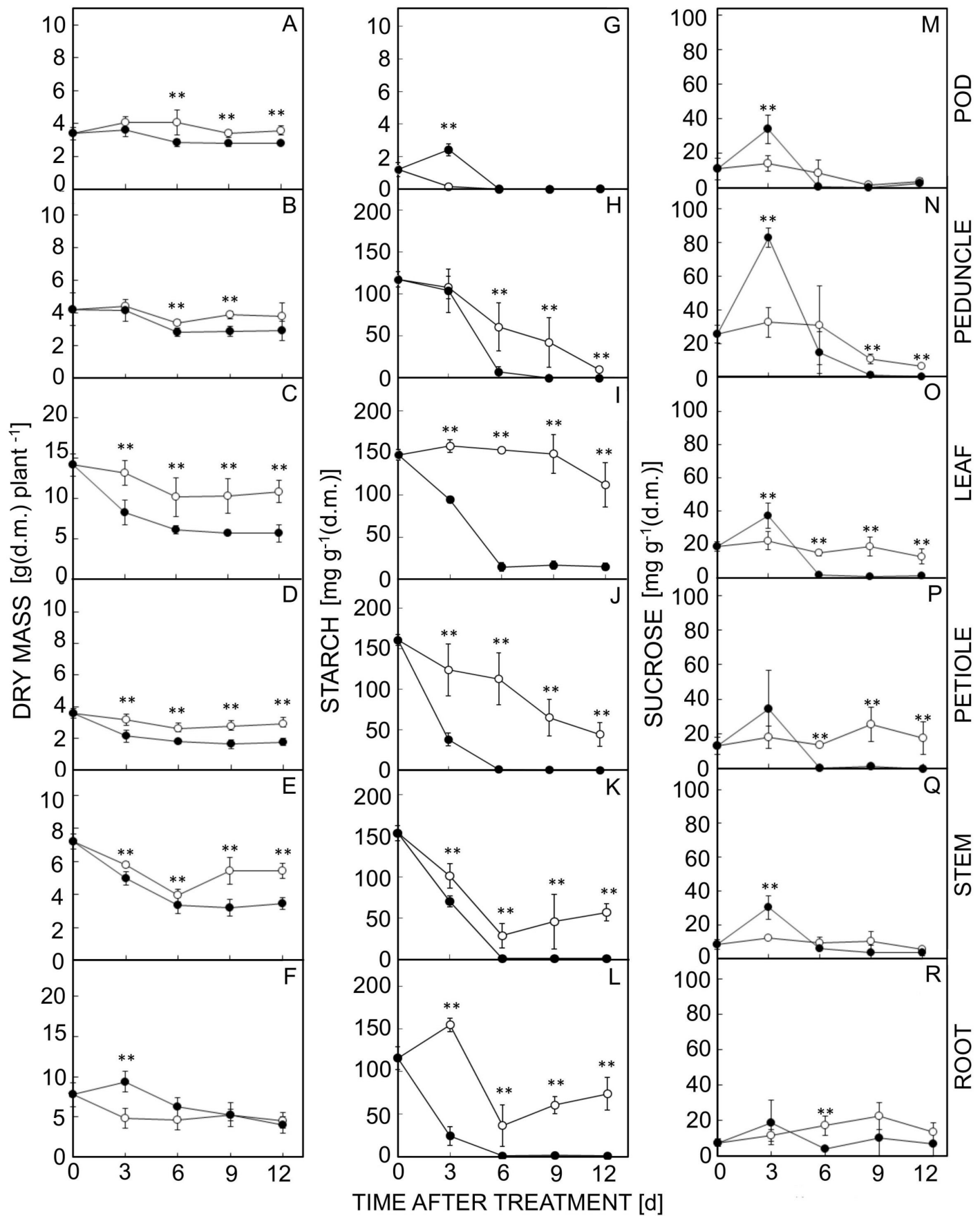

Fig. 3. Dry mass, starch, and sucrose content of source organs of cowpea under drought stress during grain filling in 2009 (open circles - control; closed circles - drought stress). Means \pm SDs $n=5$, asterisks indicate significant differences $(P<0.01$, Student's $t$-test $)$.

was higher on day 3 than that of the corresponding control, but decreased below the control after $6 \mathrm{~d}$ (Fig. $3 M-R)$. The dry masses of pod and peduncle also decreased compared with control at $6 \mathrm{~d}$ after drought stress, although the starch and sucrose content increased at $3 \mathrm{~d}$ after drought stress. These results indicated that the pod and peduncle temporarily act as sink organ, and then as source organ. In contrast, the dry mass and starch content of developing seeds under drought stress were maintained at the control levels (Fig. 4). In drought-stressed common bean, assimilates accumulate in grain despite an early reduction in photosynthetic rate (Boutraa and Sanders 2001). In rice, wheat, and chickpea, drought stress at grain filling promote the conversion of starch in the leaf and stem to sucrose, and its transport to the grain (Davies et al. 2000, Yang et al. 2001a, Yang et al. 2003). The evidence we obtained in this study also indicates that cowpea promotes the translocation of assimilates to its grain under drought stress at grain filling stage via rapid degradation of starch in all source organs. 


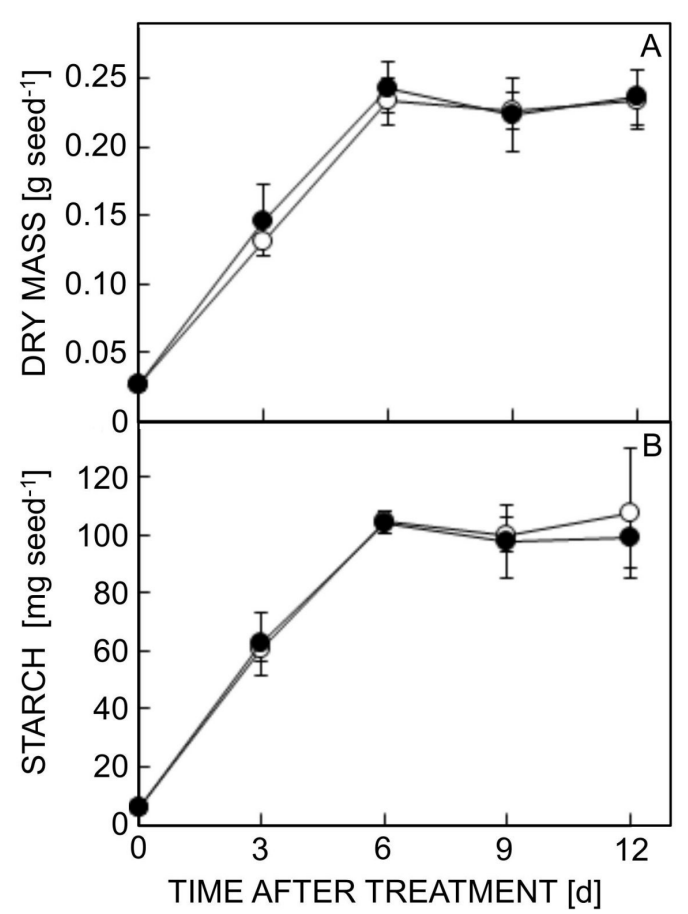

Fig. 4. Dry mass $(A)$ and starch content $(B)$ of developing cowpea seeds under drought stress during grain filling in 2009 (open circles - control; closed circles - drought stress). Means \pm SDs, $n=5$.

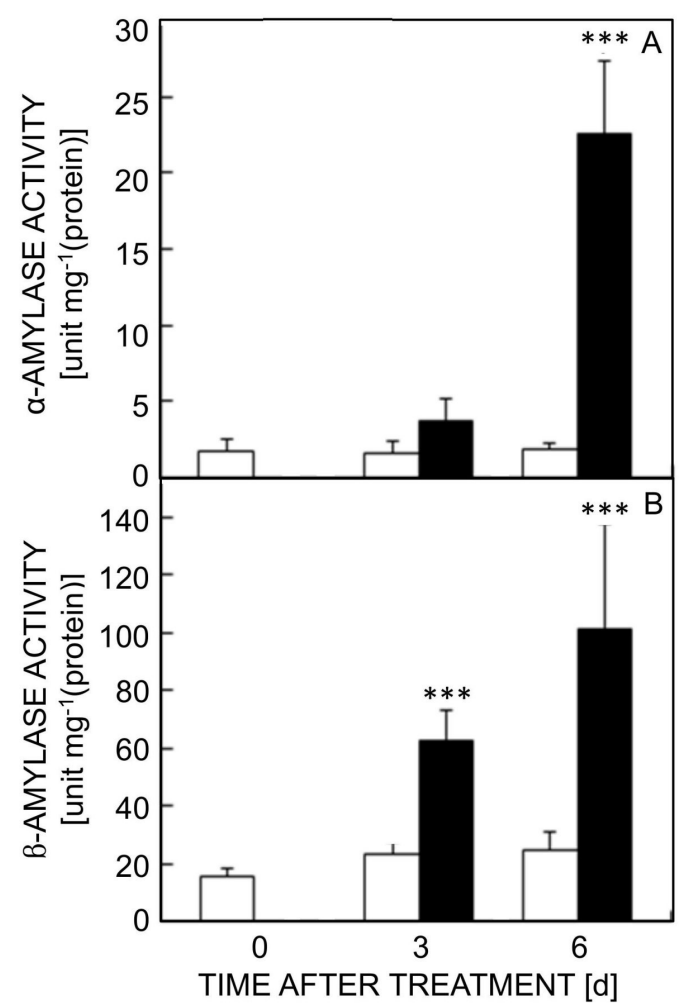

Fig. 5. Activities of $\alpha$-amylase $(A)$ and $\beta$-amylase $(B)$ in leaves of cowpea under drought stress during grain filling in 2009 (open circles - control; closed circles - drought stress). Means \pm SDs, $n=5$, asterisks indicate significant differences $(P<0.01$, Student's $t$-test).
Examination of the $\alpha$ - and $\beta$-amylase activities was conducted in the leaves which showed the most rapid and significant degradation of starch among the source organs under drought stress (Fig. 2I). While only $\beta$-amylase plays an important role in the degradation of starch in leaf in Arabidopsis (Lao et al. 1999, Kaplan and Guy 2005, Yu et al. 2005), it has been reported that the activities of both $\alpha$ - and $\beta$-amylase increased under drought stress in rice, barley, and cucumber (Jacobsen et al. 1986, Todaka et al. 2000, Yang et al. 2001b). In cowpea, both $\alpha$ - and $\beta$-amylase activities increased under drought stress (Fig. 5). Compared to the $\alpha$-amylase activity, the $\beta$-amylase activity showed quicker and greater increase under drought stress at grain filling period.

In this study, cowpea could maintain its grain yield with small reduction of 100-grain mass under drought stress at grain filling stage (Table 1), though the immediate suppression of photosynthesis was observed (Fig. 1B). While the suppression of photosynthesis was occurred, the rapid degradation of photoassimilates in source organs under drought stress was observed (Fig. 2). Also, the rapid increment of both $\alpha$ - and $\beta$-amylase activities which may be involved in the degradation of photoassimilates in source organs was indicated (Fig. 4). Thus, our study provides the evidence that the rapid translocation of photoassimilates to the grain contributes to the maintenance of grain yield under conditions of drought stress at grain filling stage in cowpea.

\section{References}

Bates, L.M., Hall, A.E.: Stomatal closure with soil water depletion not associated with changes in bulk leaf water status. - Oecologia 50: 62-65, 1981.

Boutraa, T., Sanders, F.E.: Influence of water stress on grain yield and vegetative growth of two cultivars of bean (Phaseolus vulgaris L.). - J. Agron. Crop Sci. 187: 251-257, 2001.

Boyer, J.S.: Plant productivity and environment. - Science 218 : 443-448, 1982.

Bray, E.A., Bailey-Serres, J., Weretilnyk, E.: Responses to abiotic stresses. - In: Gruissem, W., Buchannan, B., Jones, R., (ed.): Biochemistry and Molecular Biology of Plants. Pp. 11581249. American Society of Plant Physiologists, Rockville 2000.

Brevedan, R.E., Egli, D.B.: Short periods of water stress during seed filling, leaf senescence and yield of soybean. - Crop Sci. 43: 2083-2088, 2003.

Davies, S.L., Turner, N.C., Palta, J.A., Siddique, K.H.M., Plummer, J.A.: Remobilization of carbon and nitrogen supports seed filling in chickpea subjected to water deficit. Aust. J. agr. Res. 51: 855-866, 2000.

Fussell, L.K., Bidinger, F.R., Bieler, P.: Crop physiology and breeding for drought tolerance: research and development. Field Crops Res. 27: 183-199, 1991.

Hiler, E.A, Van Babel C.H.M., Hossain M.M., Jordan W.R.: Sensitivity of southern peas to plant water deficit at three growth stages. - Agron. J. 64: 60-64, 1972.

Imamura, M., Egashira, C., Ishinabshi, Y., Iwaya-Inoue, M.: Characteristics of water-related parameters of roots, leaves and hypocotyls in cowpea under drought stress compared with common bean. - Cryobiol. Cryotechnol. 56: 43-49, 2010. Jacobsen, J.V., Hanson, A.D., Chandler, P.C.: Water stress 
enhances expression of an $\alpha$-amylase gene in barley leaves. Plant Physiol. 80: 350-359, 1986.

Kaplan, F., Guy, C.L.: RNA interference of Arabidopsis betaamylase 8 prevents maltose accumulation upon cold shock and increases sensitivity of PS II photochemical efficiency to freezing stress. - Plant J. 44: 730-743, 2005.

Lao, N.T., Schoneveld, O., Mould, R.M., Hibberd, J.M., Gray, J.C., Kavanagh T.A.: An Arabidopsis gene encoding a chloroplast-targeted $\beta$-amylase. - Plant J. 20: 519-527, 1999.

Liu, F.L., Andersen, M.N., Jensen, C.R.: Loss of pod set caused by drought stress is associated with water status and ABA content of reproductive structures in soybean. - Funct. Plant Biol. 30: 271-280, 2003.

Muchero, W., Ehlers, J.D., Roberts, P.A.: Seedling stage droughtinduced phenotypes and drought-responsive genes in diverse cowpea genotypes. - Crop Sci. 48: 541-552, 2008.

Ogbonnaya, C.I., Sarr, B., Brou, C., Diouf, O., Diop, N.N., RoyMacauley, H.: Selection of cowpea genotypes in hydroponics, pots and field for drought tolerance. - Crop Sci. 43: 11141120, 2003.

Osonubi, O.: Responses of cowpeas (Vigna unguiculata (L.) Walp.) to progressive soil drought. - Oecologia 66: 554-557, 1985.

Pate, J.S., Peoples, M.B., Atkins, C.A.: Post-anthesis economy of carbon in a cultivar of cowpea. - J. exp. Bot. 34: 544-562, 1983.

Phan, T., Ishibashi, Y., Miyazaki, M., Huong, T., Okamura, K., Tanaka, S., Nakamura, J., Yuasa, T., Iwaya-Inoue M.: High temperature-induced repression of the rice sucrose transporter (OsSUT1) and starch synthesis-related genes in sink and source organs at milky ripening stage causes chalky grains. J. Agron. Crop Sci. 199: 178-188, 2013.

Saito, K., Mahmood, T., Kuroda, T.: Effect of moisture stress at different growth stages on flowering and pot set in determinate and indeterminate soybean cultivars. - Jap. J. Crop Sci. 68:
537-544, 1999.

Sakamoto, T., Hashiguchi, Y., Kurauchi, E., Imamura, M., Ishibashi, Y., Muranaka, S., Yuasa, T., Iwaya-Inoue, M.: Causative factors of decreasing flower number in cowpea under drought stress during flowering stage. - Cryobiol. Cryotechnol. 58: 81-85, 2012.

Shouse, P., Dasberg, S., Jury, W.A., Stolzy, L.H.: Water deficit effects on water potential, yield and water use of cowpeas. Agron. J. 73: 333-336, 1981.

Todaka, D., Matsushima, H., Morohashi, Y.: Water stress enhances $\beta$-amylase activity in cucumber cotyledons. - J. exp. Bot. 51: 739-745, 2000.

Turk, K.J., Hall, A.E., Asbell, C.W.: Drought adaptation of cowpea. I. Influence of drought on seed yield. - Agron. J. 72: 413-420, 1980.

Yang, J.C., Zhang, J.H., Wang, Z.Q., Zhu, Q.S., Wang, W.: Remobilization of carbon reserves in response to water deficit during grain filling of rice. - Field Crops Res. 71: 47-55, 2001a.

Yang, J.C., Zhang, J.H., Wang, Z.Q., Zhu, Q.S.: Activities of starch hydrolytic enzymes and sucrose-phosphate synthase in the stems of rice subjected to water stress during grain filling. - J. exp. Bot. 52: 2169-2179, $2001 \mathrm{~b}$.

Yang J.C., Zhang, J.H., Wang, Z.Q., Zhu Q.S., Liu L.J.: Involvement of abscisic acid and cytokinins in the senescence and remobilization of carbon reserves in wheat subjected to water stress during grain filling. - Plant Cell Environ. 26: 1621-1631, 2003

Yu, T.S., Zeeman, S.C., Thorneycroft, D., Fulton, D.C., Dunstan, H., Lue, W.L., Hegemann, B., Tung, S.Y., Umemoto, T., Chapple, A., Tsai, D.L., Wang, S.M., Smith, A.M., Chen, J., Smith, S.M.: $\alpha$-Amylase is not required for breakdown of transitory starch in Arabidopsis leaves. - J. biol. Chem. 280: 9773-9779, 2005. 